\title{
DNA Repair Inhibition
}

National Cancer Institute

\section{Source}

National Cancer Institute. DNA Repair Inhibition. NCI Thesaurus. Code C40661.

DNA Repair Inhibition involves interference with, or restraint of, the enzymatic restoration of a continuous two-stranded DNA molecule without mismatch from a molecule that contains regions damaged by chemical or radiation exposure or by spontaneous damage. 